\title{
Pseudonormalisation of the ECG in a patient with life-threatening hyperkalemia
}

\author{
Paweł Wróbel (D, Andrzej Jaroszyński \\ Collegium Medicum, Jan Kochanowski University in Kielce, Poland
}

\section{Abstract}

We described a case of patient with life-threatening hyperkalemia, cardiovascular and chronic kidney disease, in which hyperkalemia instead of typical electrocardiographic changes occurred as pseudonormalization of the electrocardiogram.

Key words: hyperkalemia, ECG, CKD, CHF

Folia Cardiologica 2021; 16, 5: 338-342

\section{Introduction}

Elevated serum potassium levels are commonly found in patients with chronic kidney disease (CKD) and chronic heart failure (CHF). The deterioration of the functioning of one of these organs affects the functioning of the other; this relationship is referred to as type 2 or type 4 cardio-renal syndrome (CRS) [1]. The prevalence of renal impairment in CHF patients is estimated at $25-40 \%$ [2, 3]. Depending on the stage of CKD, hyperkalemia was observed in $2-35 \%$ of patients. In CHF patients, the incidence of this disorder is estimated at 1.4-6\% [4,5]. The reasons include reduced kaliuretic capacity, progressive loss of glomerular filtration rate, superimposed acute renal failure (ARF), diet containing potassium-rich foods, taken medications [potassium supplements, angiotensin-converting enzyme (ACE) inhibitors, sartans, potassium-sparing diuretics such as spironolactone and amiloride, calcineurin inhibitors, heparin, non-steroidal anti-inflammatory drugs (NSAIDs), cotrimoxazole, beta $_{2}$-blockers] as well as disorders of potassium distribution in the body [6]. The elevated potassium levels in the extracellular space of the heart result in a reduction of action potential duration and slowing of conduction velocity. On electrocardiogram (ECG) recording, this contributes to widening of QRS complexes, $P$ wave reduction that leads to complete $\mathrm{P}$ wave disappearance, formation of peaked
T waves reflecting more synchronous ventricular repolarisation [7, 8]. Symptoms of hyperkalemia include muscle pain; paresthesias; muscle weakness, especially in the proximal parts of the limbs; cardiac arrhythmias in the form of bradycardia; ectopic beats mostly of ventricular origin. Failure to diagnose correctly may lead to cardiac arrest due to asystole. The occurrence of the aforementioned characteristic changes in the ECG recording depends on the severity of hyperkalemia; the ECG recording may also be affected by any previously detected abnormalities in the patient's ECG [9].

\section{Case report}

A 71-year-old female patient was referred to a neurology hospital for a suspected stroke. The most common complaints reported by the patient included dizziness, malaise and muscle weakness in all extremities.

\section{History of comorbidities:}

- ischaemic heart disease (IHD);

- history of 3 myocardial infarctions treated with angioplasty and coronary-artery bypass grafting;

- chronic systolic heart failure;

- hypertension;

- type 2 diabetes;

- CKD at stage G4.

Address for correspondence: Paweł Wróbel MD, PhD, Collegium Medicum, Uniwersytet Jana Kochanowskiego w Kielcach, al. IX Wieków Kielc 19A, 25-317 Kielce, Poland, e-mail: pwrobelek07@gmail.com

This article is available in open access under Creative Common Attribution-Non-Commercial-No Derivatives 4.0 International (CC BY-NC-ND 4.0) license, allowing to download articles and share them with others as long as they credit the authors and the publisher, but without permission to change them in any way or use them commercially. 
Taken drugs: beta-2blocker, converting enzyme inhibitor, torasemide, spironolactone, acetylsalicylic acid, statin, gliclazide.
On neurological examination, there were no abnormalities other than weakened muscle strength.

The additional tests performed are shown in Table 1.

Table 1. Tests performed on hospital admission

\begin{tabular}{|c|c|c|c|c|}
\hline Parameter & Value & Unit & Reference interval & Notes \\
\hline \multicolumn{5}{|l|}{$\mathrm{CBC}+$ leukocytes + platelets } \\
\hline WBC & 8.58 & $\mathrm{~K} / \mu \mathrm{L}$ & $4.10-10.90$ & \\
\hline $\mathrm{RBC}$ & 4.79 & $\mathrm{M} / \mu \mathrm{L}$ & $3.60-5.20$ & \\
\hline $\mathrm{Hb}$ & 13.0 & $g / d L$ & $12.0-15.6$ & \\
\hline HCT & 41.4 & $\%$ & $35.0-46.0$ & \\
\hline MCV & 86.4 & $\mathrm{fL}$ & $80.0-97.0$ & \\
\hline $\mathrm{MCH}$ & 27.1 & pg & $27.0-34.0$ & \\
\hline $\mathrm{MCHC}$ & 31.4 & $g / d L$ & $32.0-36.0$ & L \\
\hline PLT & 252.0 & $\mathrm{~K} / \mu \mathrm{L}$ & $140.0-440.0$ & \\
\hline Urea & 115 & $\mathrm{mg} / \mathrm{dL}$ & $20-45$ & H \\
\hline Creatinine & 2.59 & $\mathrm{mg} / \mathrm{dL}$ & $0.70-1.30$ & $\mathrm{H}$ \\
\hline Creatinine clearance (MDRD) & 19.7 & $\mathrm{ml} / \mathrm{min}$ & $75.0-110.0$ & L \\
\hline Sodium $\left(\mathrm{Na}^{+}\right)$ & 134 & $\mathrm{mEq} / \mathrm{L}$ & $137-146$ & L \\
\hline Potassium $\left(\mathrm{K}^{+}\right)$ & 9.70 & $\mathrm{mEq} / \mathrm{L}$ & $3.50-5.20$ & H \\
\hline Glucose & 106 & $\mathrm{mg} / \mathrm{dL}$ & $70-99$ & $\mathrm{H}$ \\
\hline CPK & 228 & $U / L$ & $45-300$ & \\
\hline CK-MB & 14 & $\mathrm{U} / \mathrm{L}$ & $0-39$ & \\
\hline Troponin T hs & 19.5 & $\mathrm{ng} / \mathrm{L}$ & $0.0-14.1$ & $\mathrm{H}$ \\
\hline AST & 27 & $\mathrm{U} / \mathrm{L}$ & $5-50$ & \\
\hline ALT & 19 & $\mathrm{U} / \mathrm{L}$ & $5-50$ & \\
\hline Amylase & 51 & $U / L$ & $10-108$ & \\
\hline CRP & 0.63 & $\mathrm{mg} / \mathrm{L}$ & $0.10-5.00$ & \\
\hline Prothrombin time PT & 12.8 & $\mathrm{~s}$ & $9.4-12.5$ & $\mathrm{H}$ \\
\hline Prothrombin index & 90 & $\%$ & $70-130$ & \\
\hline INR & 1.1 & & $0.8-1.2$ & \\
\hline $\begin{array}{l}\text { Activated partial thromboplastin } \\
\text { time (APTT) }\end{array}$ & 26.2 & s & $25.0-36.9$ & \\
\hline Thrombin time $\pi$ & 15.2 & $\mathrm{~s}$ & $11.0-17.8$ & \\
\hline
\end{tabular}

Non-contrast head CT

There are no signs of intracranial haemorrhage or recent vascular lesions. The ventricular system is not displaced, not dilated, not compressed. Massive calcifications in the walls of the intracerebral arteries

\section{PA chest X-ray}

Lung fields without focal lesions or parenchymal densities. The cardiac silhouette is not enlarged. Aorta with atherosclerotic plaques. Status post CABG - visible opacities of metal sutures on the sternum and opacities of vascular clips on the cardiac silhouette

\section{Abdominal ultrasound}

Kidneys are typically located, of normal size, without stasis, without deposits, with preserved parenchyma-sinus differentiation. A right renal cortical cyst with a $3 \mathrm{~mm}$ in diameter. Other abdominal organs without abnormalities

PLT - platelets; WBC - white blood cells; RBC - red blood cells; Hb - hemoglobin; HCT - hematocrit; MCV - mean corpuscular volume; MCH - mean corpuscular hemoglobin; MCHC - mean corpuscular hemoglobin concentration; $\mathrm{L}$ - low (value below the reference range); $\mathrm{H}$ - high (value above the reference range); MDRD - Modification of Diet in Renal Disease; $\mathrm{CPK}$ - creatine phosphokinase; $\mathrm{CK}$-MB creatine kinase myocardial bound; hs - high-sensitivity; ALT - alanine aminotransferase; AST - aspartate aminotransferase; TT - thrombin time; APTT - activated partial thromboplastin time; CT - computed tomography; PA - posterior-anterior; CABG - coronary artery bypass grafting; USG - ultrasonography 


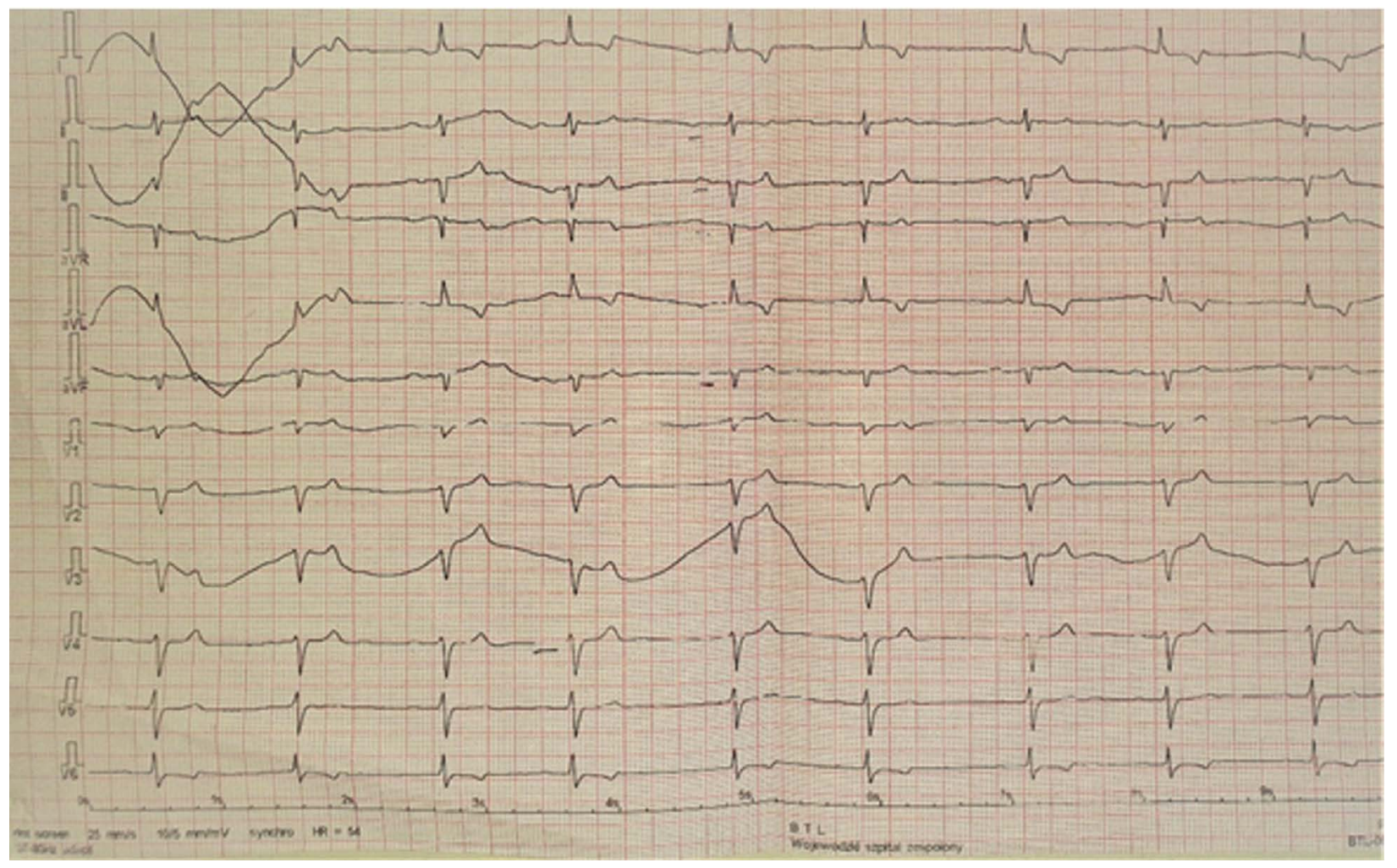

Figure 1. Electrocardiogram on hospital admission

On the ECG recording: sinus rhythm: 54/min.; negative $T$ wave in leads I, aVL; $R$ wave in leads $V 2-V 4$, biphasic T wave in lead V6; PQ $0.28 \mathrm{~s}$ (Figure 1). The ECG recording did not show any changes typical of hyperkalemia found in laboratory tests $(9.7 \mathrm{mmol} / \mathrm{l})$; abnormalities only include first-degree atrioventricular (AV) block and non-specific changes concerning the repolarisation period.

In the absence of signs of a recent stroke and the presence of life-threatening hyperkalemia, the patient was referred for further nephrology treatment. Emergency haemodialysis (HD) was performed using the dialysis fluid (dialysate) containing potassium at $4 \mathrm{mmol} / \mathrm{L}$. After HD was performed, the control serum potassium level was $6.5 \mathrm{mmol} / \mathrm{L}$ the following day. Moreover, pharmacological treatment was modified during hospitalisation by discontinuation of the ACE inhibitor and spironolactone. Complaints were eliminated; gradual improvement in muscle strength was observed after several hours of hospitalisation. Laboratory test results at hospital discharge are shown in Table 2. The control electrocardiogram revealed the T-wave reversal in precordial leads (negative T waves in leads I, aVL, V4-V6), normalisation of the PQ interval duration with a sinus rhythm of $65 / \mathrm{min}$. (Figure 2 ).

\section{Discussion}

The patient in question was diagnosed with type 2 cardiorenal syndrome (CRS) and life-threatening hyperkalemia. Finding characteristic ECG changes is helpful in making this diagnosis. However, such changes may not be observed in patients with initially modified ECG recording. The pathophysiological disturbances of muscle cell function that are induced by hyperkalemia in patients with ischaemic heart disease (positivisation in action potential, shortening of action potential duration, slowing of conduction velocity) do not differ from those found in healthy persons; however, the final shape of ECG recording may be affected by pre-existing changes in the repolarisation period. In such cases, there is a tendency to TQ-segment depression, ST-segment elevation and, frequently, reversal of previously negative T waves $[7,8]$. This presents a difficulty in making a correct diagnosis. In the case of the patient in question, the ECG recording on admission did not suggest the presence of severe hyperkalemia $(9.5 \mathrm{mmol} / \mathrm{L})$. The found abnormalities included only the slightly prolonged PQ interval ( $280 \mathrm{~ms}$ ), negative T wave in leads I, aVL and biphasic T wave in lead V6. On the other hand, the evaluation of the control ECG recording showed the 
Table 2. Tests performed at hospital discharge

\begin{tabular}{|c|c|c|c|c|}
\hline Parameter & Value & Unit & Reference interval & Notes \\
\hline \multicolumn{5}{|l|}{ WBC + leukocytes + platelets } \\
\hline WBC & 8.70 & $\mathrm{~K} / \mu \mathrm{L}$ & $4.10-10.90$ & \\
\hline $\mathrm{RBC}$ & 4.46 & $\mathrm{M} / \mu \mathrm{L}$ & $3.60-5.20$ & \\
\hline $\mathrm{HGB}$ & 12.8 & $\mathrm{~g} / \mathrm{dL}$ & $12.0-15.6$ & \\
\hline HCT & 39.3 & $\%$ & $35.0-46.0$ & \\
\hline MCV & 88.1 & $\mathrm{fL}$ & $80.0-97.0$ & \\
\hline $\mathrm{MCH}$ & 28.7 & pg & $27.0-34.0$ & \\
\hline $\mathrm{MCHC}$ & 32.6 & $\mathrm{~g} / \mathrm{dL}$ & $32.0-36.0$ & \\
\hline PLT & 227.0 & $\mathrm{~K} / \mu \mathrm{L}$ & $140.0-440.0$ & \\
\hline Urea & 80 & $\mathrm{mg} / \mathrm{dL}$ & $20-45$ & $\mathrm{H}$ \\
\hline Creatinine & 2.03 & $\mathrm{mg} / \mathrm{dL}$ & $0.70-1.30$ & $\mathrm{H}$ \\
\hline Creatinine clearance (MDRD) & 25.66 & $\mathrm{ml} / \mathrm{min}$ & $75.0-110.0$ & L \\
\hline Sodium $\left(\mathrm{Na}^{+}\right)$ & 141 & $\mathrm{mEq} / \mathrm{L}$ & $137-146$ & \\
\hline Potassium $\left(\mathbf{K}^{+}\right)$ & 5.60 & $\mathrm{mEq} / \mathrm{L}$ & $3.50-5.20$ & $\mathrm{H}$ \\
\hline $\mathrm{Ca}^{++}$ & 4.94 & $\mathrm{mEq} / \mathrm{L}$ & $4.50-5.50$ & \\
\hline Phosphorus & 3.60 & $\mathrm{mg} / \mathrm{dL}$ & $2.50-4.80$ & \\
\hline CPK & 368 & $\mathrm{U} / \mathrm{L}$ & $45-300$ & $\mathrm{H}$ \\
\hline CK-MB & 17 & $U / L$ & $0-39$ & \\
\hline Troponin Ths & 28.2 & $\mathrm{ng} / \mathrm{L}$ & $0.0-14.1$ & $\mathrm{H}$ \\
\hline Uric acid & 6.00 & $\mathrm{mg} / \mathrm{dL}$ & $3.40-7.00$ & \\
\hline $\mathrm{HbA}_{1 \mathrm{c}}$ & 5.78 & $\%$ & $4.60-6.50$ & \\
\hline
\end{tabular}

PLT - platelets; WBC - white blood cells; RBC - red blood cells; Hb - hemoglobin; HCT - hematocrit; MCV - mean corpuscular volume; MCH - mean corpuscular hemoglobin; MCHC - mean corpuscular hemoglobin concentration; $\mathrm{L}$ - low value below the reference range); $\mathrm{H}$ - high (value above the reference range); MDRD - Modification of Diet in Renal Disease; CPK - creatine phosphokinase; CK-MB creatine kinase myocardial bound; hs - high-sensitivity; $\mathrm{HbA}_{1 \mathrm{c}}$ - glycated hemoglobin

appearance of negative $T$ waves over the entire anterolateral wall (I, aVL, V4-V6) and normalisation of the PQ interval duration. Therefore, the T-wave pseudo-normalisation found in the first ECG recording in the patient in question can be considered equivalent to the high peaked $\mathrm{T}$ waves that are typical of persons without ischaemic heart disease.

\section{Summary}

Hyperkalemia is a common complication found in the population of patients with CKD and comorbid cardiovascular conditions. In this group of patients, symptoms of CKD are frequently uncharacteristic and typical electrocardiographic changes may be absent despite the existence of a serious threat to life. In patients with coronary artery disease, the equivalent of the typical hyperkalemia changes may be pseudo-normalisation of the ECG recording in terms of ST segment and T waves.

\section{Conflict of interest}

The authors declare no conflict of interest. 

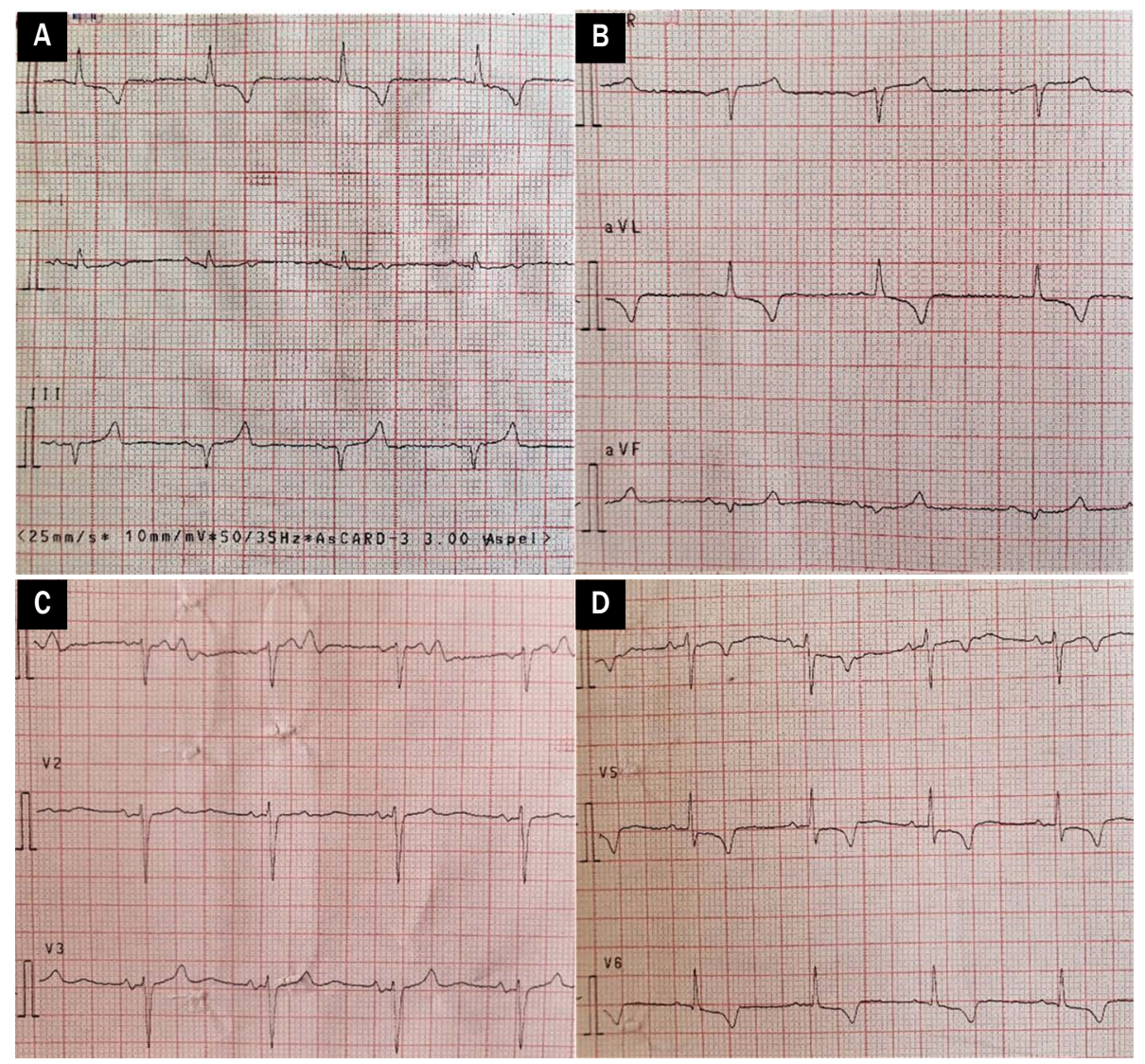

Figure 2A-D. Electrocardiogram at discharge

\section{References}

1. Ronco C, House AA, Haapio M. Cardiorenal syndrome: refining the definition of a complex symbiosis gone wrong. Intensive Care Med. 2008; 34(5): 957-962, doi: 10.1007/s00134-008-1017-8, indexed in Pubmed: 18251008.

2. Ronco C, Haapio M, House A, et al. Cardiorenal syndrome. J Am Coll Cardiol. 2008; 52(19): 1527-1539, doi: 10.1016/j.jacc.2008.07.051.

3. Zaborowski T, Dziurzyńska M, Jaroszyński A. Zespoły sercowo-nerkowe: patofizjologia, epidemiologia, postępowanie. Forum Med Rodz. 2013; 7(2): 67-74.

4. Palmer BF, Clegg DJ, Palmer BF, et al. Physiology and pathophysiology of potassium homeostasis. Adv Physiol Educ. 2016; 40(4): 480-490, doi: 10.1152/advan.00121.2016, indexed in Pubmed: 27756725 .

5. Desai AS. Hyperkalemia in patients with heart failure: incidence, prevalence, and management. Curr Heart Fail Rep. 2009; 6(4):
272-280, doi: 10.1007/s11897-009-0037-1, indexed in Pubmed: 19948096.

6. Tromp J, Meer Pv. Hyperkalaemia: aetiology, epidemiology, and clinical significance. Eur Heart J. 2019; 21(Suppl_A): A6-A11, doi: 10.1093/ /eurheartj/suy028.

7. Clausen $\mathrm{T}$. Na+-K+ pump regulation and skeletal muscle contractility. Physiol Rev. 2003; 83(4): 1269-1324, doi: 10.1152/ /physrev.00011.2003, indexed in Pubmed: 14506306.

8. Weiss JN, Qu Z, Shivkumar K. Electrophysiology of hypokalemia and hyperkalemia. Circ Arrhythm Electrophysiol. 2017; 10(3), doi: 10.1161/CIRCEP.116.004667, indexed in Pubmed: 28314851.

9. Montague BT, Ouellette JR, Buller GK. Retrospective review of the frequency of ECG changes in hyperkalemia. Clin J Am Soc Nephrol. 2008; 3(2): 324-330, doi: 10.2215/CJN.04611007, indexed in Pubmed: 18235147. 